\title{
Long-term dominance of Mycobacterium tuberculosis Uganda family in peri-urban Kampala-Uganda is not associated with cavitary disease
}

Eddie M Wampande ${ }^{1,10}$, Ezekiel Mupere ${ }^{2,4}$, Sara M Debanne ${ }^{3}$, Benon B Asiimwe', Mary Nsereko ${ }^{4}$, Harriet Mayanja ${ }^{2,4}$, Kathleen Eisenach ${ }^{5}$, Gilla Kaplan ${ }^{6}$, Henry W Boom7, Sebastien Gagneux ${ }^{8,9}$ and Moses L Joloba ${ }^{1,4,11^{*}}$

\begin{abstract}
Background: Previous studies have shown that Mycobacterium tuberculosis (MTB) Uganda family, a sub-lineage of the MTB Lineage 4, is the main cause of tuberculosis (TB) in Uganda. Using a well characterized patient population, this study sought to determine whether there are clinical and patient characteristics associated with the success of the MTB Uganda family in Kampala.

Methods: A total of 1,746 MTB clinical isolates collected from1992-2009 in a household contact study were genotyped. Genotyping was performed using Single Nucleotide Polymorphic (SNP) markers specific for the MTB Uganda family, other Lineage 4 strains, and Lineage 3, respectively. Out of 1,746 isolates, 1,213 were from patients with detailed clinical data. These data were used to seek associations between MTB lineage/sub-lineage and patient phenotypes.

Results: Three MTB lineages were found to dominate the MTB population in Kampala during the last two decades. Overall, MTB Uganda accounted for $63 \%(1,092 / 1,746)$ of all cases, followed by other Lineage 4 strains accounting for 22\% $(394 / 1,746)$, and Lineage 3 for $11 \%(187 / 1,746)$ of cases, respectively. Seventy-three $(4 \%)$ strains remained unclassified. Our longitudinal data showed that MTB Uganda family occurred at the highest frequency during the whole study period, followed by other Lineage 4 strains and Lineage 3. To explore whether the long-term success of MTB Uganda family was due to increased virulence, we used cavitary disease as a proxy, as this form of TB is the most transmissible. Multivariate analysis revealed that even though cavitary disease was associated with known risk factors such as smoking (adjusted odds ratio (aOR) 4.8, 95\% confidence interval (Cl) 3.33-6.84) and low income (aOR 2.1, 95\% Cl 1.47-3.01), no association was found between MTB lineage and cavitary TB.
\end{abstract}

Conclusion: The MTB Uganda family has been dominating in Kampala for the last 18 years, but this long-term success is not due to increased virulence as defined by cavitary disease.

Keywords: Mycobacterium tuberculosis complex, Lineage, Single nucleotide polymorphism, Mycobacteria, Strain family, Cavitation, Virulence, Epidemiology, Evolution

\footnotetext{
* Correspondence: moses.joloba@case.edu

'Department of Medical Microbiology, College of Health Sciences, Makerere

University, Kampala, Uganda

${ }^{4}$ Uganda-Case Western Reserve University Research Collaboration, Kampala, Uganda

Full list of author information is available at the end of the article
} 


\section{Background}

Globally there are seven human-associated Mycobacterium tuberculosis complex (MTBC) lineages that are differentially distributed with certain lineages predominating in certain geographical regions and human populations [1-4]. Increasing evidence shows that these lineages differ in pathogenesis in animal models, but their differential impact on tuberculosis (TB) in humans is not clear [3]. There is also inconclusive data with respect to whether the distribution of MTBC lineages/sublineages is due to host and or microbial factors [3,5,6]. Recent studies in Uganda indicated that the majority of $\mathrm{TB}$ cases are due to the MTBC Uganda family (L4-U) $[7,8]$, a sub-lineage of Lineage 4 defined by a deletion in the Region of Difference (RD) 724, the spoligotype finger print (33-36, 40 and 43 spacers missing), and several SNPs $[1,9,10]$. Although earlier studies had defined this L4-U family as Mycobacterium africanum sub-type II based on colony morphology and biochemical tests $[11,12]$, advances in molecular classification have led to its reclassification as $M$. tuberculosis sensu stricto [13].

The resurgence of TB calls for improved understanding of the epidemiology, pathogenesis, chemotherapy, and genetic variability of the causative agent for better control of the disease. Studies so far offer limited information about the kinetics of L4-U, and do not explain why this family of MTBC is so predominant in Uganda. However, it is now apparent that host, environment and microbiological factors are likely to play a role [2,9,14-22]. For instance, the dominance of Lineage 2 (which includes the Beijing family of MTBC) in Asia and its wide geographical distribution might be partially due to higher virulence (as determined in animal models) and its association with drug resistance [23-25]. Furthermore, based on the long-standing association between MTBC and its human host, some studies have proposed that the different MTBC lineages might have adapted to different human populations, perhaps as a consequence of co-evolutionary processes [1,6,23,26-28].

With the advent of robust molecular markers and a well characterized large human population cohort, genetic variability in MTBC clinical isolates and clinical phenotypes can be better described, and thus the reason of dominance of certain MTBC lineages may be deduced [3]. In this study we used MTBC isolates collected from patients participating in two large prospective community-based TB transmission studies carried out in peri-urban Kampala from 1992-2009 to establish trends in the prevalence of the various MTBC lineages over time, and examine the association of MTBC lineages with patient characteristics.

\section{Methods}

\section{Patient recruitment and collection of MTBC isolates}

The isolates used in this study were collected from patients recruited in two studies that were both carried out in peri-urban Kampala-Uganda in sequence. An initial household contact study (HC) was conducted from 1992 to 1999 to describe the epidemiology of TB [population 1.7 million; population density $9400 / \mathrm{km}^{2}$ (Uganda Bureau of Statistics; www.ubos.org, 2011) and $[29,30]$. The second study is the Kawempe Community Health study $(\mathrm{KCH})$ that started in 2000 and is ongoing. The $\mathrm{KCH}$ focuses on host factors associated with primary infection, re-infection, reactivation, and progression from MTB infection to active TB clinical disease and also identifies and tracks strains of MTB circulation in households and the local community.

During the conduct of these epidemiologic cohort studies ( $\mathrm{HC}$ and $\mathrm{KCH}$ ), adults with sputum smear positive TB were consecutively enrolled as index cases. An index case was defined as the first TB case identified in a household who was $\geq 18$ years of age and lived with one or more household contacts. A household was defined as a group of people living within one residence, share meals together and identified a head of family who made decisions for the household. Following the identification of the index cases, home health visitors contacted the household contacts for health education about TB and the study. A household contact was defined as any individual who had resided in the household for at least 7 consecutive days during the 3 months prior to the diagnosis of TB in the index case. Household contacts were screened for both latent (tuberculin skin test) and active disease (sputum smear and culture) on first contact. Those found not to have TB according to the study protocol were followed every three months for a period of two years to identify contacts that later developed active TB. Household contacts were classified as coprevalent cases if active $\mathrm{TB}$ was present at baseline or during three months of household follow-up and as incident cases if active TB developed after three months of follow-up. In both studies ( $\mathrm{HC}$ and $\mathrm{KCH}$ ) a total of 1746 isolates were stored from the study area over the period of study (1995-2009). Patients with either latent or active $\mathrm{TB}$ were treated with isoniazid (INH) preventive therapy or standard short course combination chemotherapy for active TB in accordance with the Uganda National TB and Leprosy Program guidelines.

At baseline, data of enrolled patients, including age, sex, HIV status, presence of cavity, ethnicity, status of smoking, Body Mass Index (BMI), level of education, alcohol drinking, income, history of diabetes, presence of BCG scar, night sweats, TB in the past, hemoptysis, swollen lymph nodes, extent of disease on chest radiographs and smear grade, were recorded. The extent of disease on chest radiographs was classified as normal, mild, moderate, or far advanced using a validated, standardized scheme [31], with lesions recorded by an independent reader who was blinded to smear and culture 
results. Sputum smear microscopy and culture were performed at either the National TB Reference Laboratory (NTRL) or the Joint Clinical Research Centre (JCRC) TB Laboratory. Isolates were confirmed as MTB using the BACTEC $^{\ominus}$ para-nitro-acetyl amino-hydroxy-propiophenone (NAP) susceptibility method [32] and later stored at $-80^{\circ} \mathrm{C}$ in $7 \mathrm{H} 9$ broth supplemented with OADC and glycerol for future analyses.

The institutional review boards and ethics committees at Case Western Reserve University, Makerere University, and the Ugandan AIDS Research Council, and the Uganda National Council for Science and Technology approved the study protocols. All patients gave written informed consent for study participation, including pre- and postHIV test counseling.

\section{Extraction of MTBC genomic DNA from stored isolates}

A total of 1,746 isolates were stored in replicates at either JCRC or NTRL laboratories at $-80^{\circ} \mathrm{C}$. Isolates corresponding to an individual patient were selected for genotyping. To extract DNA, the selected isolates were thawed overnight at $-20^{\circ} \mathrm{C}$ and later at room temperature for $12 \mathrm{~h}$. The vials were centrifuged at $15,000 \mathrm{~g}$ for $30 \mathrm{~min}$ and the pellet washed twice with $500 \mu \mathrm{l}$ of Qiagen PCR water. The final pellet was re-suspended in $100 \mu \mathrm{l}$ of Qiagen PCR-water, heated at $95^{\circ} \mathrm{C}$ for 30 minutes to kill and lyse the bacilli and later sonicated for $15 \mathrm{~min}$ at room temperature. The extracted genomic DNA in the supernatant was recovered by centrifugation at $15,000 \mathrm{~g}$ for $30 \mathrm{~min}$; the latter was used immediately in the real time PCR (RT-PCR) assay or stored at $-20^{\circ} \mathrm{C}$ for future use.

\section{Genotyping MTBC isolates with Single Nucleotide Polymorphic (SNP) markers by RT-PCR assay}

To ascertain the lineage of an MTB isolate, RT-PCR (Roche Light Cycler ${ }^{\circ} 480$ ) was performed using specific primers and hybridization probes (HyProbe, FRET probes) containing SNPs designed based on the work published by Comas et al. [9] and Hershberg et al. [10] (See Additional file 1: Table S1). RT-PCR analysis involved, amplification $\left(40\right.$ cycles of $95^{\circ} \mathrm{C}$ for 10 s, $57 / 53 / 51^{\circ} \mathrm{C}$ for $10 \mathrm{~s}$ and $72^{\circ} \mathrm{C}$ for $10 \mathrm{~s}$ ) of the target region(s) to generate amplicons for melting curve analysis. Melting curves were analyzed using lightCycler ${ }^{\circ}$ software version 1.5 to assign an isolate to a particular lineage depending on the melting temperature $(\mathrm{Tm})$ at which the hybridization probes dissociates from the amplicons. For validation purposes, Long Sequence Polymorphism PCR (LSP-PCR) analysis was performed as previously described $[1,20]$. In all the assays, we used MTB L4-U genomic DNA from our laboratory, $\mathrm{H} 37 \mathrm{Rv}$ genomic DNA (Lineage 4) and Lineage 3 (Central Asian strain) genomic DNA (Courtesy of Mark Nicol) as positive control DNA.
Identification of MTBC lineages in the clinical isolates collected from peri-urban Kampala

A total of eight (8) SNPs, 3 for identifying MTB Uganda (L4-U): (Rv0006_0238n, Rv0040c-0619n and Rv2949c0375s); 2 for MTB Lineage 4: (Rv 0407-0960s and Rv 2962c-0711) and then 3 for MTB Lineage 3: (Rv 0129c_0472n, Rv 2959c-0219n and Rv 3133c-0419) each with its accompanying designed primers and probes were optimized for use in RT-PCR SNP assays to identify MTBC lineages on the basis of differences in melting temperature (Tm). Since the SNPs identifying each lineage were mutually exclusive, we selected a single SNP from each lineage, which provided reliable results, for genotyping the 1,746 MTB isolates. For the Uganda family sub lineage we selected 2 SNPs, one for identifying Uganda I and the other for Uganda II MTB (See Additional file 1: Table S1). Genotyping results based on the designed RT-PCR SNP assay were consistent with that based on long sequence polymorphism (LSP) (data not shown).

\section{Statistical analysis}

Patient characteristics were compared using the chi-square test for binary data and Student's t-test for continuous variables. A series of univariate and multivariable logistic regression models were fitted to evaluate the relationship between MTB lineage (primary independent variable) and severity of TB disease on chest radiograph (cavitary TB) or smear status (dependent variable). Lung cavitation as a radiographic variable was used as a measure for severity of disease since it is associated with worse symptoms of TB $[33,34,35]$. Age, sex, HIV status and other patient characteristics were used as covariates (See Table 1).

In order to predict the transmission dynamics over a span of 18 years, we performed a trend analysis using Poisson regression analysis with MTB lineage as the main predictor variable and adjustment for years. All analyses were performed using SAS version 9.2 (SAS Institute, Cary, NC).

\section{Results}

Overall and time-point prevalence of MTBC lineages in peri-urban Kampala from 1992-2009

In a RT-PCR SNP genotyping assay, a total of 1,746 MTBC isolates, each from a different TB patient, were analyzed. Overall, 63\% (1092/1,746) were L4-U, 22\% $(394 / 1,746)$ were other Lineage 4 strains [from now onwards these shall be referred to as Lineage 4 non Uganda (L4-NU)], and 11\% (187/1,746) Linage 3 (L3). The remaining 73 (4\%) strains could not be classified based on the genotyping techniques used (Additional file 2: Figure S1). Next, we determined the point prevalence of the three predominant MTBC lineages during the previous 18 years (1992 to 2009). The data suggest that 
Table 1 Distribution of patient variables across the 3 main MTB lineages in peri-urban Kampala

\begin{tabular}{|c|c|c|c|c|c|c|}
\hline Variable & Category & Patients characteristics ( $n, \%)$ & L4-U ( $n=788)$ & L4-NU ( $n=289)$ & L $3(n=136)$ & P-value* \\
\hline \multirow[t]{2}{*}{ Age $^{1}$} & $>30$ years & $757(69)$ & $503(70)$ & $173(66)$ & $81(68)$ & 0.44 \\
\hline & $\leq 30$ years & $340(31)$ & $213(30)$ & $89(34)$ & $38(32)$ & \\
\hline \multirow[t]{2}{*}{$\operatorname{Sex}^{2}$} & Female & $503(46)$ & $325(45)$ & $120(46)$ & $58(49)$ & 0.79 \\
\hline & Male & $594(54)$ & $391(55)$ & $142(54)$ & $61(51)$ & \\
\hline \multirow[t]{2}{*}{ HIV status $^{3}$} & Negative & $669(65)$ & $450(66)$ & $157(62)$ & $62(60)$ & 0.29 \\
\hline & positive & $367(35)$ & $230(34)$ & $95(38)$ & $42(40)$ & \\
\hline \multirow[t]{2}{*}{ Cavity $^{4}$} & No & $441(47)$ & $296(48)$ & $106(48)$ & $39(39)$ & 0.25 \\
\hline & Yes & $500(53)$ & $324(52)$ & $115(52)$ & $61(61)$ & \\
\hline \multirow[t]{2}{*}{ Ethnicity $^{5}$} & Non-bantu & $64(6)$ & $39(6)$ & $14(6)$ & $11(9)$ & 0.27 \\
\hline & Bantu & $984(94)$ & $641(94)$ & $238(94)$ & $105(91)$ & \\
\hline \multirow[t]{2}{*}{ Smoking $^{6}$ status } & Never smoked & $659(62)$ & $443(65)$ & $155(60)$ & $61(52)$ & 0.03 \\
\hline & Current or ever smoked & $401(38)$ & $243(35)$ & $102(40)$ & $56(48)$ & \\
\hline \multirow[t]{2}{*}{$\mathrm{BMI}^{7}$} & Weight loss & $557(49)$ & $374(50)$ & $121(44)$ & $62(48)$ & 0.19 \\
\hline & No loss & $588(51)$ & $368(50)$ & $154(56)$ & $66(52)$ & \\
\hline \multirow[t]{2}{*}{ Level of education ${ }^{8}$} & Low & $377(35)$ & $248(36)$ & $93(36)$ & $36(31)$ & 0.52 \\
\hline & High & $688(65)$ & $444(64)$ & $163(64)$ & $81(69)$ & \\
\hline \multirow[t]{2}{*}{ Drinking alcohol ${ }^{9}$} & Yes & $162(21)$ & $106(21)$ & $40(21)$ & $16(22)$ & 0.99 \\
\hline & No & $611(79)$ & $402(79)$ & $151(79)$ & $58(78)$ & \\
\hline \multirow[t]{2}{*}{ Income $e^{10}$} & Low & $270(46)$ & $162(44)$ & $69(46)$ & $39(61)$ & 0.048 \\
\hline & High & $314(54)$ & 203(56) & $82(54)$ & $29(39)$ & \\
\hline \multirow[t]{2}{*}{ diabetic Patients $^{11}$} & Yes & $12(1)$ & $8(2)$ & $3(2)$ & $1(2)$ & 0.97 \\
\hline & No & $922(99)$ & $604(98)$ & $224(98)$ & $94(98)$ & \\
\hline \multirow[t]{2}{*}{ Presence of BCG scar ${ }^{12}$} & Yes & $756(62)$ & $488(62)$ & $183(63)$ & $85(63)$ & 0.92 \\
\hline & No & $456(38)$ & $299(38)$ & $106(37)$ & $51(38)$ & \\
\hline \multirow[t]{2}{*}{ Night sweets ${ }^{13}$} & No & $533(47)$ & $340(46)$ & 133(49) & $60(47)$ & 0.69 \\
\hline & Yes & $608(53)$ & $401(54)$ & 139(51) & $68(53)$ & \\
\hline \multirow[t]{2}{*}{ TB in the past ${ }^{14}$} & Yes & $17(2)$ & $10(2)$ & $3(2)$ & $4(4)$ & 0.18 \\
\hline & No & $953(98)$ & $619(98)$ & $239(98)$ & $95(96)$ & \\
\hline \multirow[t]{2}{*}{ Hemoptysis ${ }^{15}$} & No & $173(15)$ & $111(15)$ & $43(16)$ & $19(15)$ & 0.95 \\
\hline & Yes & $972(85)$ & $632(85)$ & $231(84)$ & $109(85)$ & \\
\hline \multirow[t]{2}{*}{ Swollen lymph nodes ${ }^{16}$} & No & $46(6)$ & $26(5)$ & $16(8)$ & $4(5)$ & 0.26 \\
\hline & Yes & $727(94)$ & $482(95)$ & $175(91)$ & $70(95)$ & \\
\hline \multirow[t]{2}{*}{ Extent of lung involvement ${ }^{17}$} & Normal/mild & $733(73)$ & $475(72)$ & $180(75)$ & $78(76)$ & 0.58 \\
\hline & Advance/far advanced & $271(27)$ & $185(28)$ & $61(25)$ & $25(24)$ & \\
\hline \multirow[t]{2}{*}{ Smear grade ${ }^{18}$} & $\leq 10 \mathrm{AFB} /$ field & $227(33)$ & $146(33)$ & $65(37)$ & $16(24)$ & 0.1377 \\
\hline & >10 AFB/field & $454(67)$ & $294(67)$ & $109(63)$ & $51(76)$ & \\
\hline
\end{tabular}

*p-value obtained by chi-square statistic; $1=116$ missed data for age, $2=116$ missed data for sex, $3=177$ missed data for HIV status, $4=272$ missed data for cavity, $5=165$ missed data for ethnicity, $6=153$ missed data for smoking status, $7=68$ missed data for BMI, $8=148$ missed data for level of education, $9=440$ missed data for drinking alcohol, $10=633$ missed data for income, $11=279$ missed data for diabetes history, 12=1 missed data for BCG status, $13=72$ missed data for night sweating, 14= 243 missed data for history of TB, 15=68 missed data for hemoptysis, $16=440$ missed data for swollen glands, $17=209$ missed data for extent of lung involvement, $18=532$ misses data of smear grade.

there was no trend over time for any MTBC lineage (Additional file 3: Figure S2). However, there were significant differences in MTBC lineage frequency over time (Poisson regression analysis, $\mathrm{P}<0.0001$ ), with
L4- $\mathrm{U}$ having the highest frequency during the whole study period, followed by L4-NU and L3. The difference in frequencies remained significantly different over the years examined (Figure 1). To explore the 


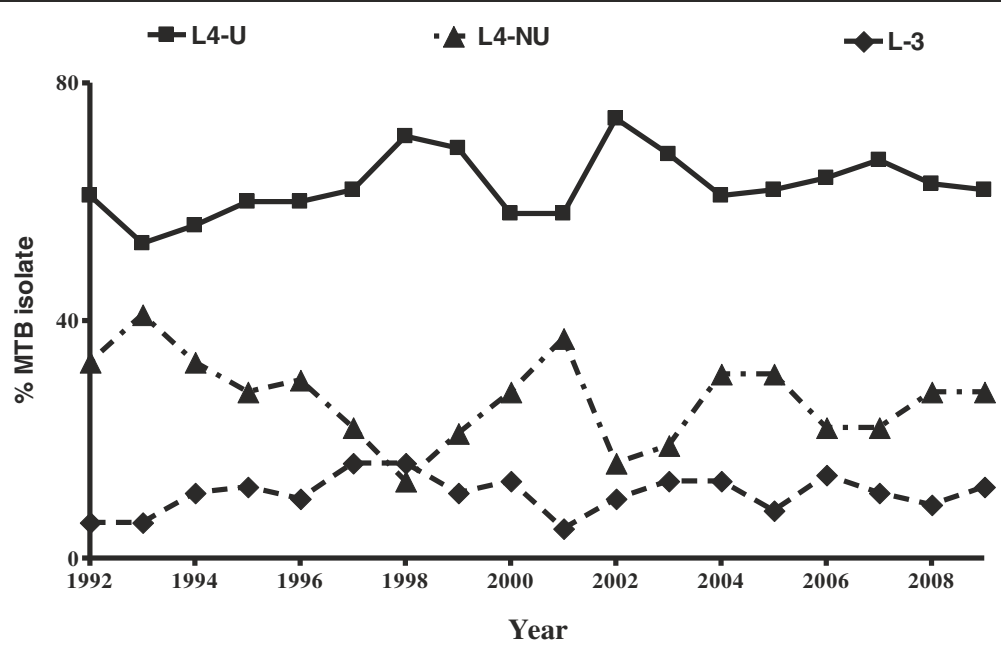

Figure 1 M. tuberculosis Uganda (L4-U) dominance over L4-NU and L3 has been stable between 1992-2009. MTBC lineages were identified as described in the legend of Figure 1. Each data point [1992 (n=109), $1993(n=71) 1994(n=94), 1995(n=73) 1996(n=80), 1997(n=82)$, 1998 (n=42), 1999 ( $n=63) 2000$ (n=88), 2001 ( $n=68) 2002(n=151), 2003$ ( $n=148), 2004(n=87), 2005(n=119) 2006(n=70), 2007(n=132) 2008$ $(n=102), 2009(n=94)]$ represent proportions of MTBC lineages observed per year.

possible underlying basis for the long-term success of L4-U compared to the other lineages circulating in Kampala, we compiled and analyzed detailed clinical data.

\section{Patient characteristics across MTBC lineages}

Of the 1,746 MTBC isolates we genotyped initially, we excluded 533 (31\%) for this part of the analysis because they lacked patient information or were of unknown lineage. Hence, a total of 1,213 (69\%) isolates remained corresponding to one TB patient each. The detailed patient characteristics of all of these patients are listed in Table 1.

Our univariate analysis taking lineage as the outcome showed that the proportions of patients infected with each MTBC lineage did not differ according to age, sex, HIV/TB co-infection, ethnicity, BMI, level of education, taking alcohol, history of diabetes, presence of BCG scar, night sweats, history of $\mathrm{TB}$ in the past, hemoptysis, swollen glands, extent of lung involvement or smear grade status (Table 1). However, we found that the proportion of TB patients with cavitary disease differed by MTBC lineage; however, this difference was not statistically significant (Table 1). Since cavitary disease is positively correlated with transmission and thus a measure of "virulence" [36], we decided to further investigate this difference, while controlling for the additional variables associated with cavitary TB.

\section{Patient risk factors associated with cavitary TB in peri-urban Kampala}

Our univariate analysis taking cavitary $\mathrm{TB}$ as the outcome confirmed that the difference between MTBC lineages was not statistically significant. But other factors were significantly associated with cavitary $\mathrm{TB}$ and included a history of smoking (OR 4.78; 95\% CI 3.41-6.69), low income (OR 2.13, 95\% CI 1.52-2.97 and hemoptysis (OR 2.10 95\% CI 1.46-3.03 (Table 2). Our multivariable logistic regression analysis with MTBC lineage as the main predictor and after adjusting for age, HIV status, history of smoking, income of the patients, and hemoptysis, again confirmed that the odds of having cavitary TB did not differ significantly between the 3 MTBC lineages (Table 3). The factors independently

Table 2 Association between MTB lineages and patient characteristics with cavitary TB

\begin{tabular}{|c|c|c|c|c|}
\hline Variable & Category & $\begin{array}{l}\text { Odds } \\
\text { Ratio }^{\odot}\end{array}$ & $95 \% \mathrm{Cl}$ & *P-value \\
\hline \multirow[t]{3}{*}{ Lineage } & Lineage L4-NU & 1 & - & - \\
\hline & Uganda (L4-U) & 0.90 & $0.69-1.18$ & 0.45 \\
\hline & Lineage 3 & 1.43 & $0.94-2.19$ & 0.10 \\
\hline \multirow[t]{2}{*}{ Age } & $>30$ years & 1 & & \\
\hline & $\leq 30$ years & 1.13 & $0.85-1.49$ & 0.40 \\
\hline \multirow[t]{2}{*}{ Sex } & Female & 1 & & \\
\hline & Male & 1.24 & $0.96-1.60$ & 0.10 \\
\hline \multirow[t]{2}{*}{ HIV status } & Negative & 1 & & \\
\hline & Positive & 0.78 & $0.596-1.03$ & 0.08 \\
\hline \multirow[t]{2}{*}{ Smoking status } & Never smoked & 1 & & \\
\hline & Current or ever smoked & 4.78 & $3.41-6.69$ & $<0.0001$ \\
\hline \multirow[t]{2}{*}{ Income } & High & 1 & & \\
\hline & Low & 2.13 & $1.52-2.97$ & $<0.0001$ \\
\hline \multirow[t]{2}{*}{ Hemoptysis } & Yes & 1 & & \\
\hline & No & 2.10 & $1.46-3.03$ & $<0.001$ \\
\hline
\end{tabular}

*p-value obtained by logistic regression analysis; @Unadjusted OR = Odds ratio. 


\begin{tabular}{|c|c|c|c|c|}
\hline Variable & Category & $\begin{array}{l}\text { Odds } \\
\text { ratio }^{\otimes}\end{array}$ & $95 \% \mathrm{Cl}$ & P-value* \\
\hline \multirow[t]{3}{*}{ Lineage } & Lineage L4-NU & 1 & - & - \\
\hline & Uganda (L4-U) & 1.08 & $0.78-1.51$ & 0.6422 \\
\hline & Lineage 3 & 1.32 & $0.78-2.22$ & 0.296 \\
\hline \multirow[t]{2}{*}{ Age } & $>30$ years & 1 & - & - \\
\hline & $\leq 30$ years & 0.866 & $0.63-1.20$ & 0.38 \\
\hline \multirow[t]{2}{*}{ HIV status } & Negative & 1 & - & - \\
\hline & Positive & 0.62 & $0.45-0.84$ & 0.0023 \\
\hline \multirow[t]{2}{*}{ Smoking status } & Never smoked & 1 & - & - \\
\hline & Current or ever smoked & 4.76 & $3.33-6.84$ & $<0.0001$ \\
\hline \multirow[t]{2}{*}{ Income } & High & 1 & & \\
\hline & Low & 2.10 & $1.47-3.01$ & $<0.0001$ \\
\hline \multirow[t]{2}{*}{ Hemoptysis } & No & 1 & - & - \\
\hline & Yes & 1.64 & $1.10-2.42$ & 0.014 \\
\hline
\end{tabular}

*p-value obtained by logistic regression analysis; ${ }^{\circledR}$ adjusted $\mathrm{OR}=$ Odds ratio.

associated with cavitary TB included smoking (adjusted odds ratio (aOR) 4.76, 95\% CI 3.33-6.84), low income (aOR 2.10, 95\%CI 1.47-3.01), signs of hemoptysis (aOR 1.64, 95\%CI 1.10-2.42) and HIV status (aOR 0.62 95\% CI 0.45-0.84 for HIV-positive patients) (Table 3).

\section{Discussion}

In this study, we sought to understand the basis for the long-term success of the MTB Uganda family in Kampala, Uganda. First, we examined the MTBC population structure and changes in prevalence of the different MTBC lineages circulating in Kampala during the last 18 years. Secondly, we investigated the risk factors associated with cavitary TB. Our data show that in periurban Kampala there are 3 dominant MTBC lineages causing TB, with L4-U being the most predominant and stable for the last 18 years, followed by the L4-NU and L3. Additionally, our multivariate results also showed that this long-term success of L4-U was not due to increased virulence when considering cavitary $\mathrm{TB}$ as a proxy, even though cavitary TB per se was independently associated with other known risk factors such as smoking, low socio-economic status and HIV-negative status [37-42]. We also note that, from out recruitment criteria only smear positive patients were enrolled as index probably this could have reduced our chances of finding any association of MTB lineage with cavitary TB. Nevertheless, among the contacts $80 \%$ of the patients were smear negative and still this category of patients showed no association of MTB Uganda family with cavitation in a univariate analysis (data not shown).

\section{Prevalence of MTB lineages over time in peri-urban Kampala}

Our data reiterate earlier findings that reported dominance of L4-U in Uganda $[7,8,20]$. In addition, the large sample size and longitudinal nature of our sample allowed us to investigate trends over time. We found that the dominance of L4-U over other Lineage 4 strains and Lineage 3 has been constant for at least the last 18 years, even with episodes of HIV and different interventions such as introduction of anti-retrovirus drugs and promotion of condom use. Taken together, these results are in agreement with the global phylogeography of $\mathrm{MTBC}$, and show that the association between particular MTBC lineages and specific geographic settings is longstanding $[2,3,6]$.

\section{Phenotypes of MTB lineages in peri-urban Kampala}

There is increasing evidence from experiments in animal models and from clinical studies indicating that MTBC strains differ in their phenotypes [3,5,18]. For instance, the virulent $\mathrm{H} 37 \mathrm{Rv}$ laboratory strain of MTBC induces less apoptosis in macrophages that the avirulent H37Ra strain [43]. Investigations in animal models have also indicated that virulence also varies between MTBC clinical strains [24,44-47]. Data from clinical cohorts have demonstrated that some strains are associated with fever [48], more severe disease [20], higher transmissibility [49], increased ability to progress from latency to active disease [50], extra pulmonary disease [51-53], and HIV co-infection [1,28]. Given that background, in this study, we tested the hypothesis that increased virulence could be responsible for the long-term success of L4-U in Kampala. We defined virulence as the ability of MTB lineage to cause cavitary TB, hence causing severe disease which is more transmissible [36,54]. Our data showed that all lineages identified in this study area had comparable odds of causing cavitary TB. This lack of association remained even after adjusting for socioeconomic and patient clinical characteristics. However, this is contrary to an earlier smaller study that observed that L4-U was more virulent [20]. The fact that we identified other clinical risk factors previously shown to be associated with cavitary disease [37,55-61] serves as a "positive control" in our study, and supports our negative finding of the lack of association of MTBC lineage with cavitary disease.

\section{Association between MTBC variants and their human hosts}

If the long-term dominance of L4- $\mathrm{U}$ is not due to increased virulence, what else could be at the basis of its success compared to other lineages in Kampala? MTBC is known to exhibit a strong phylogeographical population structure $[1,28]$, which is also reflected at the 
"sub-lineage" level. For example, the co-called Cameroon family of MTBC is a sub-lineage of Lineage 4 and almost exclusively found in West-Africa [62]. Similarly, L4-U is mainly found in Uganda and neighboring countries, and rarely found elsewhere. Another important feature of the phylogeography of MTBC is that it remains stable even in large cosmopolitan settings such as San Francisco, London and Montreal, where at least some degree of intermingling between local and immigrant host and MTBC populations could be expected $[1,6,26,63]$. Moreover, several studies have shown that MTBC preferably transmits in sympatric host populations $[1,28]$. Based on these observations, it has been hypothesized that different MTBC lineages might have adapted to different human population, possibly as a consequence of the long co-evolutionary history of MTBC and its human host $[1,2,5,6,10,28]$. Our observation that L4-U has been dominating in Kampala for at least 2 decades is consistent with this hypothesis. However, much more work is needed to substantiate this notion, including studies that investigate the interaction between human and MTBC genetic diversity [27,64-67].

\section{Limitations of the study}

First, this study defined disease outcome at presentation; this could have limited our ability to detect other parameters that contribute to disease outcome as the disease progresses. Second, our study was neither population-based nor completely random, possibly bringing about some selection bias. Nevertheless, the strength of our study is that it is based on patient information and laboratory data collected from two large, well-characterized and systematically followed up studies conducted over a long period of time.

\section{Conclusions}

In summary, we observed 3 main MTBC lineages circulate in peri-urban Kampala, with the L4-U being predominant for the last 2 decades. We found that none of these MTBC lineages were associated with increased risk for cavitary TB.

\section{Additional files}

Additional file 1: Table S1. SNPs markers, primers and probes used in RT-PCR to genotype 1746 MTB isolates.

Additional file 2: Figure S1. M. tuberculosis Uganda ( $L 4-U)$ is the most prevalent MTBC lineage. Lineages of MTBC were identified based on the presence or absence of a defined SNP. To determine the presence or absence of each SNP, primers and hybridization probes were designed for use in a real-time PCR assay that distinguishes MTBC lineages based on differences in Tm (See Additional file 1: Table S1).

Additional file 3: Figure S2. No trend from 1992-2009 for any MTBC lineage was observed. The MTBC lineage identification and proportions observed overtime is as described in legend of Additional file 2: Figure S1. The predicted frequencies of MTBC overtime were computed by Poisson logistic regression analysis.

\section{Abbreviations}

MTBC: Mycobacterium tuberculosis complex; MTB: Mycobacterium tuberculosis; RD: Region of difference; OR: Odds ratio; aOR: Adjusted odds ratio; BCG: Bacillus Calmette-Guerin; JCRC: Joint Clinical Research Centre; NTRL: National Tuberculosis Reference Laboratory; TB: Tuberculosis; SNP: Single Nucleotide polymorphism; L4: Mycobacterium tuberculosis Lineage 4; L3: Mycobacterium tuberculosis Lineage 3; L4-U: Mycobacterium tuberculosis Uganda family; L4-NU: Mycobacterium tuberculosis lineage 4 other than Uganda family.

\section{Competing interest}

The authors declare that they have no competing interest.

\section{Authors' contributions}

MLJ, SG and WHB conceived the idea; EW, MLJ, SG, WHB, KE. GK, SD designed and performed the experiments; EW, EM and SMD analyzed the data; EW, MLJ, SG, EM, SMD, GK, KE and WHB wrote the paper. All authors read and approved the final manuscript.

\section{Acknowledgement}

We acknowledge LaShaunda Malone, Denise Johnson, Hussein Kisingo and Alfred Etwom who provided the patient and microbiological data; the leadership at JCRC and NTRL who kindly assisted in identifying the isolates that were used in the study. We thank the clinicians (Dr. Alphonse Okwera and Sarah Nsereko) the nurses, home visitors and counselors at the National Tuberculosis Treatment Centre, Mulago Hospital, for their invaluable contributions to this study. We also acknowledge the Tuberculosis Research Unit's MTB Strain Working Group (TBRU-SWG) for the advice and guidance during the execution of the work.

\section{Funding}

The study was supported by the Tuberculosis Research Unit (TBRU), established with Federal funds from the United Sates National Institutes of Allergy and Infectious Diseases \& the United States National Institutes of Health and Human Services, under Contract Nos. NO1-Al-95383 and SN 266200700022 C/NO1-Al-70022 to WHB, the National Institutes of Health Grant to MLJ (\# R01 Al075637-01), the Swiss National Science Foundation (Grant PP0033-119205 to SG) and the Carnegie Corporation of New York/ Makerere University Collaboration Grant to EW.

\section{Author details}

${ }^{1}$ Department of Medical Microbiology, College of Health Sciences, Makerere University, Kampala, Uganda. ${ }^{2}$ Department of Pediatrics and Child Health College of Health Sciences, Makerere University, Kampala, Uganda.

${ }^{3}$ Department of Epidemiology and Biostatistics, School of Medicine, Case Western Reserve University, Cleveland, OH, USA. ${ }^{4}$ Uganda-Case Western Reserve University Research Collaboration, Kampala, Uganda. ${ }^{5}$ Department of Pathology, University of Arkansas for Medical Sciences, Little Rock, AR, USA. ${ }^{6}$ Laboratory of Mycobacterial Immunity and Pathogenesis, Public Health Research Institute, University of Medicine and Dentistry, Newark, NJ, USA. ${ }^{7}$ Tuberculosis Research Unit, School of Medicine, Case Western Reserve University and University Hospitals of Cleveland, Cleveland, OH, USA. ${ }^{8}$ Department of Medical Parasitology and Infection Biology, Swiss Tropical and Public Health Institute, Basel, Switzerland. ' University of Basel, Basel, Switzerland. ${ }^{10}$ Department of Bio-molecular Resources and Biolab Sciences, College of Veterinary Medicine, Animal Resources and Bio Security, Makerere University, Kampala, Uganda. ${ }^{11}$ Department of Medical Microbiology, School of Biomedical Sciences, College of Health Sciences, Makerere University, P.O BOX 7072, Kampala, Uganda.

Received: 7 June 2013 Accepted: 7 October 2013

Published: 17 October 2013

\section{References}

1. Gagneux S, DeRiemer K, Van T, Kato-Maeda M, de Jong BC, Narayanan S, Nicol M, Niemann S, Kremer K, Gutierrez MC, et al: Variable host-pathogen compatibility in Mycobacterium tuberculosis. Proc Natl Acad Sci USA 2006, 103(8):2869-2873.

2. Gagneux S, Small PM: Global phylogeography of Mycobacterium tuberculosis and implications for tuberculosis product development. Lancet Infect Dis 2007, 7(5):328-337. 
3. Coscolla M, Gagneux S: Does M: Tuberculosis genomic diversity explain disease diversity? Drug Discov Today Dis Mech 2010, 7(1):e43-e59.

4. Firdessa R, Berg S, Hailu E, Schelling E, Gumi B, Erenso G, Gadisa E, Kiros T, Habtamu M, Hussein J, et al: Mycobacterial lineages causing pulmonary and extrapulmonary tuberculosis, ethiopia. Emerg Infect Dis 2013, 19(3):460-463.

5. Gagneux S: Host-pathogen coevolution in human tuberculosis. Philos Trans R Soc Lond B Biol Sci, 367(1590):850-859.

6. Hirsh AE, Tsolaki AG, DeRiemer K, Feldman MW, Small PM: Stable association between strains of Mycobacterium tuberculosis and their human host populations. Proc Natl Acad Sci USA 2004, 101(14):4871-4876.

7. Asiimwe BB, Koivula T, Kallenius G, Huard RC, Ghebremichael S, Asiimwe J, Joloba ML: Mycobacterium tuberculosis Uganda genotype is the predominant cause of TB in Kampala, Uganda. Int I Tuberc Lung Dis 2008, 12(4):386-391.

8. Bazira J, Matte M, Asiimwe BB, Joloba LM: Genetic diversity of Mycobacterium tuberculosis in Mbarara, South Western Uganda. Afr Health Sci 2010, 10(4):306-311.

9. Comas I, Homolka S, Niemann S, Gagneux S: Genotyping of genetically monomorphic bacteria: DNA sequencing in Mycobacterium tuberculosis highlights the limitations of current methodologies. PLoS One 2009, 4(11):e7815.

10. Hershberg R, Lipatov M, Small PM, Sheffer H, Niemann S, Homolka S, Roach JC, Kremer K, Petrov DA, Feldman MW, et al: High functional diversity in Mycobacterium tuberculosis driven by genetic drift and human demography. PLoS Biol 2008, 6(12):e311.

11. Niemann S, Rusch-Gerdes S, Joloba ML, Whalen CC, Guwatudde D, Ellner JJ, Eisenach K, Fumokong N, Johnson JL, Aisu T, et al: Mycobacterium africanum subtype II is associated with two distinct genotypes and is a major cause of human tuberculosis in Kampala, Uganda. J Clin Microbiol 2002, 40(9):3398-3405.

12. Sola C, Rastogi N, Gutierrez MC, Vincent V, Brosch R, Parsons L: Is Mycobacterium africanum subtype II (Uganda I and Uganda II) a genetically well-defined subspecies of the Mycobacterium tuberculosis complex? J Clin Microbiol 2003, 41(3):1345-1346. author reply 1346-1348.

13. Brosch R, Gordon SV, Marmiesse M, Brodin P, Buchrieser C, Eiglmeier K, Garnier T, Gutierrez C, Hewinson G, Kremer K, et al: A new evolutionary scenario for the Mycobacterium tuberculosis complex. Proc Natl Acad Sci USA 2002, 99(6):3684-3689.

14. Kato-Maeda M, Bifani PJ, Kreiswirth BN, Small PM: The nature and consequence of genetic variability within Mycobacterium tuberculosis. J Clin Invest 2001, 107(5):533-537.

15. Warren RM, Streicher EM, Sampson SL, van der Spuy GD, Richardson M, Nguyen D, Behr MA, Victor TC, van Helden PD: Microevolution of the direct repeat region of Mycobacterium tuberculosis: implications for interpretation of spoligotyping data. J Clin Microbiol 2002, 40(12):4457-4465.

16. Liu X, Gutacker MM, Musser JM, Fu YX: Evidence for recombination in Mycobacterium tuberculosis. J Bacteriol 2006, 188(23):8169-8177.

17. Niemann S, Koser CU, Gagneux S, Plinke C, Homolka S, Bignell H, Carter RJ, Cheetham RK, Cox A, Gormley NA, et al: Genomic diversity among drug sensitive and multidrug resistant isolates of Mycobacterium tuberculosis with identical DNA fingerprints. PLoS One 2009, 4(10):e7407.

18. Nicol MP, Wilkinson RJ: The clinical consequences of strain diversity in Mycobacterium tuberculosis. Trans R Soc Trop Med Hyg 2008, 102(10):955-965

19. Malik AN, Godfrey-Faussett P: Effects of genetic variability of Mycobacterium tuberculosis strains on the presentation of disease. Lancet Infect Dis 2005, 5(3):174-183.

20. Nahid P, Bliven EE, Kim EY, Mac Kenzie WR, Stout JE, Diem L, Johnson JL, Gagneux S, Hopewell PC, Kato-Maeda M: Influence of M. tuberculosis lineage variability within a clinical trial for pulmonary tuberculosis. PLoS One 2010, 5(5):e10753.

21. Mathema B, Kurepina N, Yang G, Shashkina E, Manca C, Mehaffy C, Bielefeldt-Ohmann H, Ahuja S, Fallows DA, Izzo A, et al: Epidemiologic consequences of microvariation in Mycobacterium tuberculosis. J Infect Dis 2012, 205(6):964-974.

22. Zhang FF, Michaels DC, Mathema B, Kauchali S, Chatterjee A, Ferris DC, James TM, Knight J, Dounel M, Tawfik HO, et al: Evolution of epidemiologic methods and concepts in selected textbooks of the 20th century. Soz Praventivmed 2004, 49(2):97-104.
23. Parwati I, van Crevel R, Van Soolingen D: Possible underlying mechanisms for successful emergence of the Mycobacterium tuberculosis Beijing genotype strains. Lancet Infect Dis 2010, 10(2):103-111.

24. Manca C, Tsenova L, Bergtold A, Freeman S, Tovey M, Musser JM, Barry CE 3rd, Freedman VH, Kaplan G: Virulence of a Mycobacterium tuberculosis clinical isolate in mice is determined by failure to induce Th1 type immunity and is associated with induction of IFN-alpha /beta. Proc Nat/ Acad Sci USA 2001, 98(10):5752-5757.

25. Drobniewski F, Balabanova Y, Nikolayevsky V, Ruddy M, Kuznetzov S, Zakharova S, Melentyev A, Fedorin I: Drug-resistant tuberculosis, clinical virulence, and the dominance of the Beijing strain family in Russia. JAMA 2005, 293(22):2726-2731.

26. Reed MB, Pichler VK, McIntosh F, Mattia A, Fallow A, Masala S, Domenech P, Zwerling A, Thibert L, Menzies D, et al: Major Mycobacterium tuberculosis lineages associate with patient country of origin. J Clin Microbiol 2009, 47(4):1119-1128.

27. Caws M, Thwaites G, Dunstan S, Hawn TR, Lan NT, Thuong NT, Stepniewska K, Huyen MN, Bang ND, Loc TH, et al: The influence of host and bacterial genotype on the development of disseminated disease with Mycobacterium tuberculosis. PLoS Pathog 2008, 4(3):e1000034.

28. Fenner L, Egger M, Bodmer T, Furrer H, Ballif M, Battegay M, Helbling P, Fehr J, Gsponer T, Rieder HL, et al: HIV infection disrupts the sympatric host-pathogen relationship in human tuberculosis. PLoS Genet 2013, 9(3):e1003318.

29. Guwatudde D, Nakakeeto M, Jones-Lopez EC, Maganda A, Chiunda A, Mugerwa RD, Ellner JJ, Bukenya G, Whalen CC: Tuberculosis in household contacts of infectious cases in Kampala Uganda. Am J Epidemiol 2003, 158(9):887-898.

30. Guwatudde D, Zalwango S, Kamya MR, Debanne SM, Diaz MI, Okwera A, Mugerwa RD, King C, Whalen CC: Burden of tuberculosis in Kampala Uganda. Bull World Health Organ 2003, 81(11):799-805.

31. Falk A, Pratt PC: Classification of pulmonary tuberculosis. In Diagnosis standards and classification of tuberculosis, Volume 12. Edited by Falk A, O'Connor AJB, Pratt PC, Webb JA, Weir JA, Wolinsky A. New York, NY: National Tuberculosis and Respiratory Disease Association; 1969:68-76.

32. Siddiqi SH, Hwangbo CC, Silcox V, Good RC, Snider DE Jr, Middlebrook G: Rapid radiometric methods to detect and differentiate Mycobacterium tuberculosis/M. bovis from other mycobacterial species. Am Rev Respir Dis 1984, 130(4):634-640.

33. Bark CM, Dietze R, Okwera A, Quelapio MI, Thiel BA, Johnson JL: Clinical symptoms and microbiological outcomes in tuberculosis treatment trials. Tuberculosis (Edinb) 2011, 91(6):601-604.

34. Palaci M, Dietze R, Hadad DJ, Ribeiro FK, Peres RL, Vinhas SA, Maciel EL, Do Valle Dettoni V, Horter L, Boom WH, et al: Cavitary disease and quantitative sputum bacillary load in cases of pulmonary tuberculosis. J Clin Microbiol 2007, 45(12):4064-4066.

35. Benator D, Bhattacharya M, Bozeman L, Burman W, Cantazaro A, Chaisson R, Gordin F, Horsburgh CR, Horton J, Khan A, et al: Rifapentine and isoniazid once a week versus rifampicin and isoniazid twice a week for treatment of drug-susceptible pulmonary tuberculosis in HIV-negative patients: a randomised clinical trial. Lancet 2002, 360(9332):528-534.

36. Rodrigo T, Cayla JA, Garcia De Olalla P, Galdos-Tanguis H, Jansa JM, Miranda $P$, Brugal T: Characteristics of tuberculosis patients who generate secondary cases. Int J Tuberc Lung Dis 1997, 1(4):352-357.

37. Busi Rizzi E, Schinina V, Palmieri F, Girardi E, Bibbolino C: Cavitary pulmonary tuberculosis HIV-related. Eur J Radiol 2004, 52(2):170-174.

38. Kwan CK, Ernst JD: HIV and tuberculosis: a deadly human syndemic. Clin Microbiol Rev, 24(2):351-376.

39. Pai M, Mohan A, Dheda K, Leung CC, Yew WW, Christopher DJ, Sharma SK: Lethal interaction: the colliding epidemics of tobacco and tuberculosis. Expert Rev Anti Infect Ther 2007, 5(3):385-391.

40. Perlman DC, El-Sadr WM, Nelson ET, Matts JP, Telzak EE, Salomon N, Chirgwin K, Hafner R: Variation of chest radiographic patterns in pulmonary tuberculosis by degree of human immunodeficiency virusrelated immunosuppression. The Terry Beirn Community Programs for Clinical Research on AIDS (CPCRA). The AIDS Clinical Trials Group (ACTG). Clin Infect Dis 1997, 25(2):242-246.

41. Perlman DC, Leung CC, Yew WW: Diagnosing tuberculosis in patients with HIV: do we know enough? Am J Respir Crit Care Med 2009, 180(9):800-801.

42. West EL, Gadkowski LB, Ostbye T, Piedrahita C, Stout JE: Tuberculosis knowledge, attitudes, and beliefs among North Carolinians at increased risk of infection. N C Med J 2008, 69(1):14-20. 
43. Danelishvili L, McGarvey J, Li YJ, Bermudez LE: Mycobacterium tuberculosis infection causes different levels of apoptosis and necrosis in human macrophages and alveolar epithelial cells. Cell Microbiol 2003, 5(9):649-660.

44. Dormans J, Burger M, Aguilar D, Hernandez-Pando R, Kremer K, Roholl P, Arend SM, van Soolingen D: Correlation of virulence, lung pathology, bacterial load and delayed type hypersensitivity responses after infection with different Mycobacterium tuberculosis genotypes in a BALB/c mouse model. Clin Exp Immunol 2004, 137(3):460-468.

45. Marquina-Castillo B, Garcia-Garcia L, Ponce-de-Leon A, Jimenez-Corona ME, Bobadilla-Del Valle M, Cano-Arellano B, Canizales-Quintero S, Martinez-Gamboa A, Kato-Maeda M, Robertson B, et al: Virulence, immunopathology and transmissibility of selected strains of Mycobacterium tuberculosis in a murine model. Immunology 2009, 128(1):123-133.

46. Palanisamy GS, DuTeau N, Eisenach KD, Cave DM, Theus SA, Kreiswirth BN, Basaraba RJ, Orme IM: Clinical strains of Mycobacterium tuberculosis display a wide range of virulence in guinea pigs. Tuberculosis (Edinb) 2009, 89(3):203-209.

47. Manca C, Tsenova L, Barry CE 3rd, Bergtold A, Freeman S, Haslett PA, Musser JM, Freedman VH, Kaplan G: Mycobacterium tuberculosis CDC1551 induces a more vigorous host response in vivo and in vitro, but is not more virulent than other clinical isolates. J Immunol 1999 162(11):6740-6746

48. Thwaites $G$, Caws M, Chau TT, D'Sa A, Lan NT, Huyen MN, Gagneux S, Anh PT, Tho DQ, Torok E, et al: Relationship between Mycobacterium tuberculosis genotype and the clinical phenotype of pulmonary and meningeal tuberculosis. J Clin Microbiol 2008, 46(4):1363-1368.

49. Albanna AS, Reed MB, Kotar KV, Fallow A, Mclntosh FA, Behr MA, Menzies D: Reduced transmissibility of East African Indian strains of Mycobacterium tuberculosis. PLoS One 2011, 6(9):e25075.

50. de Jong BC, Hill PC, Aiken A, Awine T, Antonio M, Adetifa IM, Jackson-Sillah DJ, Fox A, Deriemer K, Gagneux S, et al: Progression to active tuberculosis, but not transmission, varies by Mycobacterium tuberculosis lineage in The Gambia. J Infect Dis 2008, 198(7):1037-1043.

51. Click ES, Moonan PK, Winston CA, Cowan LS, Oeltmann JE: Relationship between Mycobacterium tuberculosis Phylogenetic Lineage and Clinical Site of Tuberculosis. Clin Infect Dis 2012, 54(2):211-219.

52. Lari N, Rindi L, Cristofani R, Rastogi N, Tortoli E, Garzelli C: Association of Mycobacterium tuberculosis complex isolates of BOVIS and Central Asian (CAS) genotypic lineages with extrapulmonary disease. Clin Microbiol Infect 2009, 15(6):538-543.

53. Fenner L, Gagneux S, Janssens JP, Fehr J, Cavassini M, Hoffmann M, Bernasconi E, Schrenzel J, Bodmer T, Bottger EC, et al: Tuberculosis in HIV-negative and HIV-infected patients in a low-incidence country: clinical characteristics and treatment outcomes. PLoS One 2012, 7(3):e34186.

54. Brites D, Gagneux S: Old and new selective pressures on Mycobacterium tuberculosis. Infect Genet Evol 2012, 12(4):678-685.

55. Aderaye G, Bruchfeld J, Assefa G, Feleke D, Kallenius G, Baat M, Lindquist L: The relationship between disease pattern and disease burden by chest radiography, $M$. tuberculosis Load, and HIV status in patients with pulmonary tuberculosis in Addis Ababa. Infection 2004, 32(6):333-338.

56. Altet-Gomez MN, Alcaide J, Godoy P, Romero MA, Hernandez Del Rey I: Clinical and epidemiological aspects of smoking and tuberculosis: a study of 13,038 cases. Int J Tuberc Lung Dis 2005, 9(4):430-436.

57. Leung CC, Lam TH, Ho KS, Yew WW, Tam CM, Chan WM, Law WS, Chan CK, Chang KC, Au KF: Passive smoking and tuberculosis. Arch Intern Med 2010, 170(3):287-292.

58. Leung CC, Lam TH, Yew WW: Smoking and tuberculosis: infection, disease, and mortality. Arch Intern Med 2007, 167(18):2008-2009. author reply 2009.

59. Leung CC, Li T, Lam TH, Yew WW, Law WS, Tam CM, Chan WM, Chan CK, Ho KS, Chang KC: Smoking and tuberculosis among the elderly in Hong Kong. Am J Respir Crit Care Med 2004, 170(9):1027-1033.

60. Leung CC, Yew WW, Chan CK, Tam CM, Lam CW, Chang KC, Chau CH, Lau KS, Law WS: Smoking and tuberculosis in Hong Kong. Int J Tuberc Lung Dis 2003, 7(10):980-986.

61. Leung CC, Yew WW, Law WS, Tam CM, Leung M, Chung YW, Cheung KW, Chan KW, Fu F: Smoking and tuberculosis among silicotic patients. Eur Respir J 2007, 29(4):745-750.

62. Yeboah-Manu D, Asante-Poku A, Bodmer T, Stucki D, Koram K, Bonsu F, Pluschke G, Gagneux S: Genotypic diversity and drug susceptibility patterns among M. tuberculosis complex isolates from South-Western Ghana. PLoS One 2011, 6(7):e21906.
63. Baker L, Brown T, Maiden MC, Drobniewski F: Silent nucleotide polymorphisms and a phylogeny for Mycobacterium tuberculosis. Emerg Infect Dis 2004, 10(9):1568-1577.

64. Intemann CD, Thye T, Niemann S, Browne EN, Amanua Chinbuah M, Enimil A, Gyapong J, Osei I, Owusu-Dabo E, Helm S, et al: Autophagy gene variant IRGM -261T contributes to protection from tuberculosis caused by Mycobacterium tuberculosis but not by M. africanum strains. PLOS Pathog 2009, 5(9):e1000577.

65. Thye T, Niemann S, Walter K, Homolka S, Intemann CD, Chinbuah MA Enimil A, Gyapong J, Osei I, Owusu-Dabo E, et al: Variant G57E of mannose binding lectin associated with protection against tuberculosis caused by Mycobacterium africanum but not by M. tuberculosis. PLoS One 2011, 6(6):e20908.

66. van Crevel R, Parwati I, Sahiratmadja E, Marzuki S, Ottenhoff TH, Netea MG, van der Ven A, Nelwan RH, van der Meer JW, Alisjahbana B, et al: Infection with Mycobacterium tuberculosis Beijing genotype strains is associated with polymorphisms in SLC11A1/NRAMP1 in Indonesian patients with tuberculosis. J Infect Dis 2009, 200(11):1671-1674.

67. Thye T, Nejentsev S, Intemann CD, Browne EN, Chinbuah MA, Gyapong J, Osei I, Owusu-Dabo E, Zeitels LR, Herb F, et al: MCP-1 promoter variant $362 C$ associated with protection from pulmonary tuberculosis in Ghana West Africa. Hum Mol Genet 2009, 18(2):381-388.

doi:10.1186/1471-2334-13-484

Cite this article as: Wampande et al.: Long-term dominance of Mycobacterium tuberculosis Uganda family in peri-urban Kampala-Uganda is not associated with cavitary disease. BMC Infectious Diseases 2013 13:484.

\section{Submit your next manuscript to BioMed Central and take full advantage of:}

- Convenient online submission

- Thorough peer review

- No space constraints or color figure charges

- Immediate publication on acceptance

- Inclusion in PubMed, CAS, Scopus and Google Scholar

- Research which is freely available for redistribution

Submit your manuscript at www.biomedcentral.com/submit
C) Biomed Central 